Behavior and Social Issues, 18, 5-9 (2009). (C) Linda J. Hayes \& Mitch J. Fryling. Readers of this article may copy it without the copyright owner's permission, if the author and publisher are acknowledged in the copy and the copy is used for educational, not-for-profit purposes.

\title{
GUEST EDITORIAL: INTERDISCIPLINARY SCIENCE IN Interbehavioral Perspective
}

\author{
Linda J. Hayes ${ }^{1}$ \\ Mitch J. Fryling \\ University of Nevada, Reno
}

\begin{abstract}
As the disciplinary sciences develop there is a growing interest in interdisciplinary science. This is particularly so in certain areas of the sciences where the objects of investigation are of interest to workers in multiple scientific domains. This commentary considers the nature of science from an interbehavioral perspective. In doing so, the nature and goals of both disciplinary and interdisciplinary sciences are considered. KEYWORDS: interdisciplinary science, disciplinary science, system building, interdisciplinary relationships

As the disciplinary sciences register progress there is a growing interest in interdisciplinary science (Elkana, 2006; Hayes, 2001, 2004; National Academy of Sciences/National Academy of Engineering, \& Institute of Medicine, 2005). This commentary pursues the topic of interdisciplinary science from the perspective of J.R. Kantor's philosophy of interbehaviorism (Kantor, 1953) and system of interbehavioral psychology (Kantor, 1958). Interbehaviorism is a unique perspective in that its assumptions and goals regarding the scientific domain are explicitly outlined (Kantor, 1953, 1958; Kantor \& Smith, 1975). In other words, interbehaviorism is specifically systematized with respect to its philosophical foundation. The purpose of this commentary is to briefly outline some important assumptions of interbehaviorism and their implications toward conceptualizing both disciplinary and interdisciplinary sciences.
\end{abstract}

\footnotetext{
${ }^{1}$ Author note: Linda J. Hayes, Department of Psychology, University of Nevada, Reno; Mitch J. Fryling, Department of Psychology, University of Nevada, Reno. Mitch J. Fryling is now at Department of Applied Behavior Analysis, The Chicago School, Los Angeles. This commentary was based in part on the first author's presidential address at the Association for Behavior Analysis International 2004 Annual Conference in Boston, MA. See Hayes and Fryling (2009) for a more elaborate description of this work. Correspondence concerning this article should be addressed to Linda J. Hayes, Department of Psychology/296, University of Nevada, Reno, Reno, NV 89557. E-mail: lhayes@unr.edu
} 


\section{HAYES \& FRYLING}

\section{THE NATURE OF SCIENCE}

From the interbehavioral perspective the world is comprised of one matrix of natural happenings (Kantor, 1953). All of the factors comprising this whole are interrelated, and thus, when one of these factors is manipulated, it is the entire whole which is changed. Further, no one factor is more important or foundational than any other factor from the interbehavioral perspective (Observer, 1969a). Rather, all of the factors comprising the whole have a participatory, interrelated nature. Given this perspective, the interbehavioral position is not one that embraces any form of reductionism. Indeed, the idea that one factor is the basis or foundation of another factor has been described as the basis fallacy (Observer, 1969b), and is explicitly shunned by interbehaviorists.

Beyond the dismissal of reductionistic tendencies, it is important to note that the interbehavioral perspective thoroughly attacks dualism in all of its forms, and strongly advocates for its removal from the scientific domain (Kantor, 1953). ${ }^{2}$ Given that sciences aim to understand the world of nature, and that hypothetical entities do not exist in that world, hypothetical constructs are not to be included in any aspect of science. Toward this, interbehaviorists strongly advocate for developing constructs which are derived from contacts with events, rather than those which are derived from cultural folklore and imposed upon events (Kantor, 1953, 1957; Smith, 2007).

\section{Disciplinary Sciences}

No scientific enterprise aims to understand each and every factor participating in the interrelated matrix of natural happenings. Indeed, this task is too tall for any one science to accomplish. Kantor proposes that it is more appropriate to refer to science in the plural form, that is, as the sciences (Kantor, 1953, p. 5). Individual sciences select a part of the interrelated matrix of natural happenings as their subject matter. Importantly, we must acknowledge that this is an arbitrary procedure (Hayes \& Fryling, 2009). This is to say, the natural world is not comprised of subject matters. For example, there isn't a factor called "psychological" existing in the natural world. Rather, an aspect of the natural world is selected and called "psychological".

As there are multiple disciplinary sciences participating within the larger domain of science, the value of an individual disciplinary science is based upon its identification of a unique subject matter derived from the world of nature. Sciences that examine the same type of event may be considered redundant, and

\footnotetext{
${ }^{2}$ This attack on dualism is similar to that of radical behaviorism (e.g., Skinner, 1953).
} 
thus, their overall value is compromised. In other words, the extent to which an individual scientific discipline produces valuable information depends upon the extent to which that information is distinguished from other sciences.

The careful identification of a unique subject matter is an important step toward the development of a valuable disciplinary science. However, also central to the long term value of a disciplinary science is the sustained focus on the objects identified as the discipline's subject matter over time. Disciplinary sciences develop over extended periods of time, and the extent to which they develop useful theories, laws, and more depends upon the extent to which there is a coherent, ongoing focus on the same objects of study. A failure to focus on the same objects of study prevents the possibility of a coherent body of knowledge, and as such, the ultimate value of such a discipline is diminished. Disciplines which lack a sustained focus on the identified subject matter become particularly fragmented over time. ${ }^{3}$

It is important to reiterate that the subject matters of the disciplinary sciences are obviously interrelated (Kantor, 1953). Further, some sciences may be particularly close, as when their identified subject matters, while distinct, involve similar features (e.g., psychology and sociology). Given this, it is important that the boundary conditions between closely related individual sciences are carefully drawn. Again, where one type of event begins and stops is arbitrary, but this arbitrariness does not invalidate the importance of boundary conditions between individual scientific enterprises. Boundary conditions must be clearly drawn and closely adhered to over time. When boundary conditions are not properly drawn, or overlooked altogether, scientific work is likely to be unorganized, as when the nature of the subject matter changes across various efforts within the discipline.

Given our comments thus far, it seems obvious that disciplinary sciences do not simply develop by fiat. The development of disciplinary sciences requires consistent and specific attention to important systemic issues. Central to these issues is the identification of a unique subject matter, as well as a sustained focus on that subject matter over time. While these tasks may seem simple enough, issues pertaining to subject matter identification are often rather complex. Even more difficult is the continued focus on a specific subject matter over time. In the following section we will comment on interdisciplinary sciences.

\footnotetext{
${ }^{3}$ This fragmentation is even more likely when careful identification of the subject matter is lacking altogether.
} 


\section{HAYES \& FRYLING}

\section{Interdisciplinary Sciences}

Interdisciplinary sciences are distinguished from disciplinary sciences by the source of the derivation of their subject matters. As we have mentioned, the subject matters of disciplinary sciences are derived from the multi-factored field comprising the natural world of nature. However, this is not the case for interdisciplinary sciences. Rather, the subject matters of interdisciplinary sciences are derived from the subject matters of already existing disciplinary sciences. Specifically, the subject matters of interdisciplinary sciences are the relationships among the subject matters of the participating disciplinary sciences. While all sciences study relationships, interdisciplinary sciences study relations among relations.

Beyond this important difference, interdisciplinary sciences are similar to disciplinary sciences. Specifically, like disciplinary sciences, interdisciplinary sciences must also identify a unique relationship to examine as their special subject matters, whereby their work may be valuable toward understanding the happenings in the world. Again, if a unique relationship is not identified, the outcomes of work conducted within the interdisciplinary system will be redundant, and add little to our scientific understandings of the world.

Additional comments are warranted regarding the uniqueness of the subject matters of interdisciplinary sciences. It is true that the participants in the relationship of interdisciplinary sciences are not unique, that is, they are the subject matters of already existing disciplinary sciences. Given this, we can say that the participants in interdisciplinary subject matters are not unique. However, the relationship between these participants, that is the relationship between the subject matters of the participating disciplinary sciences, is a unique relationship. ${ }^{4}$

Also similar to disciplinary sciences, interdisciplinary sciences achieve progress by their continued focus on the same subject matter over a period of time. It is only through this prolonged focus that a coherent body of knowledge may develop and evolve. The sustained focus on the same objects of study facilitates the development of a larger set of theories, laws, and more.

Interdisciplinary sciences face additional concerns involving the systemization and general strength of the participating disciplinary sciences, as well as the manner in which the participating disciplines are positioned with respect to one another within the interdisciplinary system. While subject matter issues may become extremely complex within disciplinary systems, they are even more so within the context of interdisciplinary systems. Interdisciplinary systems require

\footnotetext{
${ }^{4}$ The uniqueness of the interdisciplinary subject matter can be compromised in many ways (see Hayes \& Fryling, 2009 for a thorough discussion).
} 


\section{INTERDISCIPLINARY SCIENCE}

the consideration of both disciplinary and interdisciplinary subject matters. Given this, it is not surprising that a number of missteps might occur along the way toward developing valuable interdisciplinary enterprises (see Hayes \& Fryling, 2009).

\section{CONCLUSION}

Our goal in this commentary was to briefly describe an interbehavioral conceptualization of both disciplinary and interdisciplinary sciences, with the primary aim of appreciating similarities and differences between them. Given the potential value that interdisciplinary sciences may offer toward understanding the complexities of the world, it is important to consider naturalistic approaches to interdisciplinary science such as the one we have described in this commentary.

\section{REFERENCES}

Elkana, Y. (2006). Unmasking uncertainties and embracing contradictions: Graduate education in the sciences. In C. M. Golde \& G. E. Walker (Eds.), Envisioning the future of doctoral education: Preparing stewards of the discipline (pp. 65-96). San Francisco: Jossey-Bass.

Hayes, L. J. (2001). Finding our place in a constructed future. In L. J. Hayes, J. Austin, R. Houmanfar, \& M. C. Clayton (Eds.), Organizational change (pp. 349-372). Reno, NV: Context Press.

Hayes, L. J. (2004). Behaviorism at 100. Presidential Address, Association for Behavior Analysis, Boston, MA. May, 2004.

Hayes, L. J., \& Fryling, M. J. (2009). Toward an interdisciplinary science of culture. The Psychological Record, 59, 679-700.

Kantor, J. R. (1953). The logic of modern science. Chicago: Principia.

Kantor, J. R. (1957). Events and constructs in the science of psychology: Philosophy-Banished and recalled. The Psychological Record, 7, 55-60.

Kantor, J. R. (1958). Interbehavioral psychology. Chicago: Principia.

Kantor, J. R., \& Smith, N. W. (1975). The science of psychology: An interbehavioral survey. Chicago: Principia.

National Academy of Sciences/National Academy of Engineering, \& Institute of Medicine (2005). Facilitating interdisciplinary research. Washington, DC: National Academies Press.

Observer (1969a). On the reduction of psychology to physics. The Psychological Record, 19, 515518.

Observer (1969b). The basis fallacy in psychology. The Psychological Record, 19, 645-648.

Skinner, B. F. (1953). Science and human behavior. New York: The Free Press.

Smith, N. W. (2007). Events and constructs. The Psychological Record, 57, 169-186. 